\title{
Ethical issues during ethnographic research in residential homes: A personal experience
}

\author{
Tabatabaei SZ, PhD* \\ - PhD in Public Health, Social Determinant of Health Research Center, Dept. of Social Medicine, Faculty of Medicine, \\ Rafsanjan University of Medical Sciences, Rafsanjan, Iran.
}

\begin{abstract}
Received: June 2016, Accepted: December 2016

Background: Ethical issues are essential components in any piece of research. In fact, they ought to be considered during designing, planning and conducting each research study particularly among the vulnerable. The aim of this paper is to describe and explain some of the ethical issues and challenges faced by a researcher who carried out a research in three Malaysian residential homes.

Materials and Methods: This paper describes the challenges experienced by a researcher during two pilot studies and a main ethnographic study in three Malaysian residential homes. For this, relevant literatures were explored as well.

Results: This manuscript is divided into three sections. First, it provides the key definitions. Second, it describes the ethical issues before entering the fields work. And third, it elaborates on the ethical considerations when researcher was making observations and writing field notes, and when the elderly participants were interviewed.
\end{abstract}

Conclusions: Better understanding of ethical considerations can help researchers to better handle their research and avoid harming others.

Keywords: Ethics, Qualitative Research, Aged, Nursing Homes

\section{Introduction}

Doing ethnographic studies in residential homes for the elderly people offers the researchers an abundance of valuable data about their quality of life $(1,2)$. Yet the residents cannot be treated with disrespect and harm, but should be given ethical considerations that compensate for their participation in the research.

The scanty information pertaining to this matter warrants such studies be done by experienced and novice ethnographers. Over twenty months of data gathering and analysis, ethical issues arising from different cultural values and humanistic aspects provided me with the hard and subtle facets of human quality. In the following sections the key definitions, the ethical issues of concern prior to entering the field work, and some elaboration on the ethics during field research are presented. This paper aims to describe and explain some of the ethical issues and challenges faced by a researcher studying three Malaysian residential homes for the elderly. In the other words, the aim of this paper is therefore to raise awareness among researchers and policy makers involve in ethical issues.

\section{Materials and Methods}

This paper describes the challenges experienced by a researcher during two pilot studies and a main ethnographic study in three Malaysian' residential homes. For this, relevant literatures were explored as well via an electronic database search such as Medline,

\footnotetext{
* Corresponding author: Seyed Zia Tabatabaei, Social Determinant of Health Research Center, Dept. of Social Medicine, Faculty of Medicine, Rafsanjan University of Medical Sciences, Rafsanjan, Iran. E-mail: seyedzia2003@yahoo.com
} 
Scopus, Google Scholar, CINAHL, PubMed and Science Direct. Search was conducted to retrieve studies from 1998-2016 using the following keywords: ethical considerations, ethical issues, elderly people, elderly residents, ethnographic studies, qualitative research, nursing home and long-term care facility. All electronic database searches were limited to research-based studies published in Persian (researcher native language) and English. Abstracts of 68 relevant studies were reviewed one by one and if there was relevant information regarding my study, whole full texts of the articles were considered. Of the 68 article, 39 articles were not relevant to my study leaving a total of 29 articles included in the final scoping review.

\section{Definitions of Concepts}

Defining Ethics: Ethics is a debatable issue and up to now, there has been no consensus on what does 'ethics' refer to. A study specifically highlights this point and believes that "ethics is difficult to define in a way that truly expresses its nature" (3). The study by Gilbert (2001: 45) defined ethics as "principled sensitivity to the rights of others" (4). Ethics can be considered as a body of moral principles or standards of human nature that conduct the behavior of individual in correct path $(5,6)$. Thus, "ethics" is about addressing the sensitivity with regard to the rights of humans $(7,8)$. In research, the pursuit of finding the truth is a respectable value, yet this has to be accompanied by respect for human dignity. Is better, even if in the extreme case, the respect for human dignity leaves one ignorant of human nature? (9). The deontological foundation for ethics suggests that there are moral imperatives we have a duty to obey because failing to do so would be a betrayal of our reason and moral sense (10). In short, ethics encompass morality and the principles underlying it (11).

Ethnography: Ethnography is an approach of observing human activities in their natural context $(12,13)$. It can also be defined as the observation of individual interactions in their familiar environment (14). In other words, ethnography is the art and science of describing a group or culture (15). The description may be that of a small group of elderly people who live in a long term care facility or a group of footballers who play in a club. Another way of defining ethnography is as asserted by Hoolachan focusing on the examination of the behaviors of a group of people, seeking to understand that groups' view of their cultural system (16).

O'Reilly (17) also emphasized on the focus of the examination of the behaviors of a group of people with the purpose of understanding that groups' view of cultural system (17). Ethnography involves not only the description of culture and events that occur within the context but also the interpretation of life ways and patterns of the group being studied (18, 19). Ethnography is a body of knowledge that consists of research techniques, with which the people are studied in their cultural context. Researchers achieved these by immersing themselves in the behavior and thoughts of the people (20). The way to get into these is by accessing the informants to explain their stories and experiences. And these are constructs used by the researcher to explain how the people shape their everyday life under a given environment (17). It is a firsthand study of a particular context and its cultural differences with other cultures as far as cultural data is concerned $(12,18)$.

In the following, I will describe the process of ethical considerations before entering residential homes till end of data collection phase.

Entering to field work: It should be noted that, to gain entry to the field work for doing research study, ethical approval has to be obtained from the supporting institute(s). For this, I obtained an ethical approval from Faculty of Medicine and Health Sciences' Ethics Committee at University Putra Malaysia (UPM) and Malaysian Welfare Department for the possibility of conducting projects in residential homes. Furthermore, I 
attached a copy of his proposal to inform gatekeepers of what I wanted to do in aforementioned settings. After this, I visited residential homes, to briefly evaluate the settings before commencing the main study. As Taylor and Bogdan (1998: 67) stated: "an awareness of the researcher's knowledge of the field before starting the study is needed; the more you know about or are involved in the field of study, the more difficult it is to study it, to see its tacit cultural rules" (20).

Moreover, in informal meetings at three residential homes, I introduced myself to managers, explained my studies (two preliminary and a main project) and answered some questions related to my researches. The main issues rose were the confidentiality of residential homes and the participants were concerned. In this regard, I assured gatekeepers that pseudonyms would be used and that none of the information would help readers identify the participants and settings. Access was easy when the scope of the research was identified clearly and information was shared regarding protection of identity and confidentiality of settings as well participants.

After gaining entry to three residential homes, following strategies were used to gather information needed: participant observation, in-depth interview and field notes. During each data collection phase, I always reviewed ethical considerations in my mind and also obligated myself to use the right ways to protect the residents.

Participant observation: For collecting data, I used participant observation as a part of methods. To achieve this, I spent much more time in different areas of residential homes to familiarize myself with these institutional settings. First of all, I began my study by watching and listening to acquire a more precise understanding of what the physical settings of these cultural societies were. And also to understand what the elderly residents did in these facilities. It was very hard to observe, especially during the first days.
Residents constantly perceived me as a stranger who was always watching, speaking, hanging around, taking notes and asking some informal questions and were perhaps more suspicious about why researcher was at setting. I felt that the residents were curious about my presence and wanted to know what I was going to do. For this, I explained about my activities in form of qualitative research. I introduced myself, as well as my position and my study to build a trust and better relationship with them and also to elicit their support and cooperation. Jamshed supported this notion by illustrating that researcher must explain the aims of the research study to those observed or interviewed in the field work (21). Therefore, I should explain to them my research due to ethical consideration, face to face or as a group, when they gathered in the same place such as the prayer room and the common room. Ethnographer, have to build relationships of trust which are essential to accurately record behavior of participants, and in fact to glean much more information from their activities and environments.

Additionally, veracity is a concept in which the researcher has an obligation to be honest and trustworthy whiles s/he deals with informants. As an ethnographer, I was obligated to be honest and respect all the people living and working there including residents, caregivers, and staff members. During first days, I introduced myself correctly and even invited some staff coming to my house build friendships to know me better and believe what I was saying and doing. Unexpectedly, one of the staff members and his wife came to my house for dinner one night.

Veracity or truthfulness requires that researcher not intentionally deceive or mislead any individual involved in the research. This principal relies on mutual trust and respect for human dignity. This is because without respect and trustworthiness, one cannot build a meaningful relationship. It is also worth noting that being honest, truthful, and sincere when 
dealing with participants is one of the best strategies to elicit their information. According to literature reviews, in specific relationships among the scholars and the informants, the nature of the qualitative approach may focus on given ethical considerations $(22,23)$. This relationship is one particular and crucial area where ethical issues have to be managed in the correct manner. As such, I attempted to be as unobtrusive as possible to ensure that they were comfortable with my presence. This was one of my beliefs that indicated that I was hyper-aware of my presence in residential homes and how I presented myself to participants in order to obtain their trust and confidence.

Furthermore, one of the most important strategies is communication with residents and listening to them carefully (24). Sometimes elderly residents invited me to listen to their stories. One resident was quoted as saying, "...only you know about my life story". Sometimes their conversations lasted about three hours and I listened to their voice with my heart. After these conversations, I felt that they were somewhat contented and then I concluded that they needed someone to listen to them. I understood this fact and attempted to just listen and support them regardless of their race, sex and beliefs and encouraged and motivated caregivers and staff to have more communication with them.

Moreover, I was continually very prudent to avoid harming any of the residents, including psychiatric cases, aging and dying persons, and physically and mentally impaired residents to prevent emotional or physical discomfort while doing the project. Ladas et al. acknowledged that the researchers should ensure that their study is free from any harm to informants (25). It is also worth noting that, the researcher's cultural and religious beliefs impact his/her perspectives related to ethical considerations. Furthermore, Islam is the religion of compassion and justice, a religion that grants man his dignity, and teaches respect towards the elderly as an essential element of humanity. Islam pays particular attention to the elderly and strongly emphasizes caring for them. The teachings prescribed in the Quran are as such; build a good relationship and respectful behavior towards older persons, such as kindly serving your parents in their old age, and also respecting all older people. In this regard, the Glorious Qur'an says:

"Your Lord has decreed that you worship none but Him, and be kind to your parents. If either or both of them reach old age with you, do not even say 'uff' to them or scold them, but speak to them in terms of honor and kindness. Lower to them the wing of humility, and say, 'My Lord! Have mercy on them, for they did care for me when I was young" (Qur'an 17:234).

Based on the religious teaching and also my cultural foundations as an Iranian, I tried to practice respectful communication and bring dignity into the relationships with elderly people. Hence, as a Muslim as well as a researcher (who is familiar with ethical issues), no harm was done to the residents while researches were carried out. I was always aware of my presence and avoided doing and saying anything to harm and pique them.

The protection of informants is an important moral concern throughout each research study from design to implementation (26). Most of ethical issues are not included in the procedures and rules of research committees. For example, during long term field work, researchers may be contaminated with some kind of infectious diseases. This kind of diseases has high potential risk for elderly residents as they are vulnerable (27). One day when I was suffering from the flu, I delayed my data gathering for one week until I was sure that I am really healthy to avoid any potential risk to the residents. As a health care professional, I believe that educational organizations such as faculties must empower researchers with education on health and infectious diseases to better undertake their 
research. The study by Hughes (2004: 936) highlights this point that "educational institutions have a responsibility to train and support students to enable them to undertake research as safely as possible" (28). Most novice ethnographers, excluding health field researchers, or even some scholars who never worked in the health care systems, are not aware about health, prevention and communicable diseases, and therefore, they pose a possible threat by contaminating participants with their infectious disease(s). Obviously, some aspects of this responsibility involve the related organizations that sponsor or support the research. This responsibility consists of providing health care education programs, precise reviews of research process for ethical considerations by the ethics committee, involving the participation of a health educator, and finally, preparing guidelines to help researchers be aware of ethical issues to ensure their own safety and health during field work to protect participants.

Another important aspect of ethical consideration was sensitivity to cultural differences between researcher and the elderly residents and to stay cognizant of the dynamics of patriarchy and colonial power relations faced by the informants (10, 29). While I was in residential homes, the background of the residents and staff had to be considered. Obviously, one of the main goals of ethnographic studies is exploring and explaining the culture of a given community (19). Hence, I was aware that all residents came from different parts of Malaysia and perhaps from overseas with diverse cultures. What is clear, the Malays, Chinese and Indians are the main ethnic groups living in the Malaysia, respectively. Cultural sensitivity during fieldwork imbued this research's approach and affected all of researcher duties and activities.

It is important to consider that, during participant observations, I encountered many ethical issues. For example, one day a female elderly resident greeted and welcomed me in main setting. She asked my name and also the reason for my presence there. After explaining to her, she told "I have a friend who looks like you, he is a doctor and I worked with him for long time". She mentioned that, "you are same as my brother and I want to help you". I thanked her and then she continued: "please take your bag and go back to your home because they want to kill you". I realized that she is suffering from some mental problems. She mentioned: "when I was in the office, I heard that they decided to kill you". That resident added "where your bag is, please take it and go". After this, I tried to calm her and speak nicely with her. I stated that "they are my friends and I am here to help you and other residents by carrying out a research, and not to worry about me". When I was in main setting, mentioned resident usually followed me and warned me to leave the place. My strategy to cope with this matter was to calm her or pretend to not see her, or even sometimes pretending to listen to her advice and attempting to leave setting. Therefore, sometimes I decided to leave the yard and go to the male wards, where she could not follow me. During data collection process, some residents and staff mentioned that they observed how I coped with this difficult patient with much respect, and they were happy about it. As a researcher and long time health care professional (about 14 years), it was essential to become a part of the studied community and to be immersed in the cultural context. This enabled me to have the proper response and conduct. I believed that, when entering a cultural setting for data collection, an ethnographer must be kind and also as unobtrusive as possible, just like 'a fly on the wall' to avoid any harm to others.

In-depth interview: In the interview phase, the important task was to obtain the participant's informed consent to indicate that they fully understood the procedure and purpose of the research and come voluntarily to participate. Hence, prior to the 
commencement of each interview, the research assistant and I explained to the participants about the research and asked them to sign the consent form if they desired to participate in the research. For the elderly residents who were illiterate or could not read the form due to their poor eyesight or any other issue, the form was read to them by the research assistant (Bahasa form) or myself (English form) followed by further explanation as required, and then one of the staff members usually signed as a witness that the testimony is authoritative and authentic. Following this, all participants were encouraged to ask their questions to clarify any concerns they might have, before and during interviews. Moreover, one week before starting interviews I posted several consent forms consisting the purpose, goals, benefits, risks, and right to withdraw at any time of interview, on the wall of common areas such as the dining hall, newspaper room, pray room, religious class and clinic. With their permission, a digital recorder was used to record the interviews. In this case, participants were informed that they have the right to refuse to record their voice and the recorder could be stopped base on their desire at any time. All interviews were conducted in the setting of the participant's choice, such as religious class (when it was empty), an empty office room or physiotherapy centre (only on weekends). It is important to note that, all questions related to the research were asked in low voices during the interviews and the respondents were asked to answer in the same manner. For convenience of the interviewee, the interview time was arranged to suit their schedules.

Another strategy during interviews was to avoid exploiting the informants and compensate them for their trouble. Based on my experience as researcher and academic member in Rafsanjan University of Medical Sciences, Iran, I was aware of the ethical issues involved in this scientific study, which is to respect human dignity. Before starting each interview, the research assistant or I explained to the interviewee that when they feel uncomfortable, they may refuse to answer any question or stop being a part of the study at any time without any repercussions. In one case, after about twenty minutes of interview with a male resident, he refused to continue and asked to cease the interview.

As a foreigner who cannot speak Malay, I felt that I needed to hire a research assistant to interview two elderly Malay residents who cannot speak English. In Malay Muslim culture, males interviewing females could be a possible point of contention, especially if they are in a cozy and private place. As such, I hired a Malay girl as a research assistant to avoid any problems in this regard. Finally, at the end of each in-depth interview, I thanked the residents for their participation and apologized for any inconvenience caused.

Field notes: As mentioned before, protecting the participants' confidentiality and privacy and also assuring them about the privacy of their information was a big concern. In this context, I assured them that pseudonyms would be used for all names and that the information they gave would not allow readers to pinpoint their identity. I emphasized that pseudonyms will be used instead of their real names in future publications. Furthermore, I informed key participants that all documents related to their interview would be removed five years after project finishes. For more protection, I wrote the field notes in the Persian language (researcher native language) instead of English, in case a copy goes missing, so that nobody can read and know about informants and their setting. Also, all interviews and field notes were kept in a locked cabinet where they could be reached only by me. Moreover, all the participants were encouraged to avoid using their true names or other identification tags while recording their voice.

\section{Conclusion}

In this paper, I have tried to make visible what takes to be better managing ethical issues regarding elderly people in residential homes 
that I was encountered. Consequently, I conducted the interrogation as an ethnographer and a socially responsible scholar, considering carefully how my presence in settings will influence the elderly residents. If ethical challenges are not handled in a proper way, these challenges may negatively affect quality of their life. This issue is also crucial in ethnographic research because ethnography gives much more opportunities for trustworthiness, intimacy, honestly, disclosure, and better relationship among participants and researchers. Finally, I was always sensitive to the beliefs, needs, autonomy, privacy, as well as the personal, social and emotional realities of elderly residents as an ethical issue. My professional experiences and academic background helped me to use ethical considerations at each stage of my study. I feel that writing down my opinions, thoughts, ideas and my experiences as an ethnographer in residential homes will help other researchers to protect vulnerable people which were outlined in this article. This paper clarifies the ethical issues that emerged as a result of my work providing an ethical sound and a true way to improve resident' quality of life.

\section{Acknowledgement}

The author would like to thank the elderly residents and staff who generously shared their knowledge and information.

Conflict of interest: None declared.

\section{References}

1. Lawrence V, Fossey J, Ballard C, Moniz-Cook E, Murray J. Improving quality of life for people with dementia in care homes: making psychosocial interventions work. $\mathrm{Br} \mathrm{J}$ Psychiatry 2012; 201(5):344-51.

2. Taylor J, Sims J, Haines TP. 'I accept it [staff assistance]; no choice': an ethnographic study of residents' attitudes towards mobility within nursing homes. Int J Older People Nurs 2014; 9(4):258-68.

3. Daniel-McKeigue CJ. Cracking the ethics code: What are the ethical implications of designing a research study that relates to therapeutic interventions with children in individual play therapy? Arts Psychother 2007; 34(3):238-48.

4. Gilbert N. Researching social life. $2^{\text {nd }}$ ed. Thousand Oaks, California, United States: SAGE publications; 2001.

5. Shahriari M, Mohammadi E, Abbaszadeh A, Bahrami M. Nursing ethical values and definitions: A literature review. Iran J Nurs Midwifery Res 2013; 18(1):1-8.

6. Kluver J, Frazier R. Haidt J. Behavioral ethics for Homo economicus, Homo heuristicus, and Homo duplex. Organ Behav Hum Decis Process 2014; 123(2):150-8.

7. Fouka G, Mantzorou M. What are the major ethical issues in conducting research? Is there a conflict between the research ethics and the nature of nursing? Health Science Journal 2011; 5(1):3-14.

8. Denburg A. A sensitive period: bioethics, human rights, and child development. Health Hum Rights 2015; 17(1):E19-30.

9. Bulmer M. The ethics of social research. In: Gilbert N, Editor. Researching social life. $2^{\text {nd }}$ ed. Thousand Oaks, California, United States: SAGE publications; 2001. P.45-57.

10. Clark Ch. Social work ethics: politics, principles and practice. $1^{\text {st }}$ ed. London, England, United Kingdom: Macmillan Publishers Ltd; 2000.

11. Chervenak FA, McCullough LB. Ethics of research in prenatal medicine. Semin Perinatol 2009; 33(6):391-6.

12. Morgan-Trimmer S, Wood F. Ethnographic methods for process evaluations of complex health behaviour interventions. Trials 2016; 17:232. doi:10.1186/s13063-016-1340-2.

13. Hassen R. Ethnography of talk in wollo. Arts and Social Sciences Journal 2016; 7:184. doi:10.4172/2151-6200.1000184

14. Liamputtong P. Qualitative research methods. $4^{\text {th }}$ ed. Oxford, England, United Kingdom: Oxford University Press; 2013.

15. Angrosino M. Doing ethnography and observation research. $1^{\text {st }}$ ed. Thousand Oaks, California, United States: SAGE publications; 2007.

16. Hoolachan JE. Ethnography and homelessness research. International Journal of Housing Policy 2016; 16(1):31-49.

17. O'Reilly K. Ethnographic returning, qualitative longitudinal research and the reflexive analysis of social practice. Sociol Rev 2012; 60(3):51836.

18. Tabatabaei SZ, Azimi Bin HH, Ebrahimi F. Ethnographic exploration of elderly residents' 
perceptions and utilization of health care to improve their quality of life. World Acad Sci Eng Technol 2016; 10(7): 365-70.

19. Tabatabaei SZ, Ebrahimi F, Rahimi R, Mohd Riji H. Anybody hear us? Attempting to meet the psychological care needs of older people: an ethnographic approach. International Journal of Medical Research \& Health Sciences 2016; 5(7S):613-9.

20. Taylor SJ, Bogdan R. Introduction to qualitative research methods. $3^{\text {rd }}$ ed. Hoboken, New Jersey, United States: John Wiley \& Sons, Inc; 1998.

21. Jamshed Sh. Qualitative research methodinterviewing and observation. J Basic Clin Pharm 2014; 5(4):87-8.

22. Sanjari M, Bahramnezhad F, Fomani FK, Shoghi M, Cheraghi MA. Ethical challenges of researchers in qualitative studies: the necessity to develop a specific guideline. J Med Ethics Hist Med 2014; 7:14.

23. Palmer D. Ethical issues and their practical application in researching mental health and social care needs with forced migrants. Res Ethics 2008; 4(1):20-5.
24. Hummert ML. Challenges and opportunities for communication between age groups. In: $\mathrm{H}$. Giles, Editor. Handbook of intergroup communication. $1^{\text {st }}$ ed. Abingdon-on-Thames, United Kingdom: Routledge, Taylor \& Francis Group; 2012. P. 223-49

25. Ladas SD, Novis B, Triantafyllou K, Schoefl R, Rokkas T, Stanciu C, et al. Ethical issues in endoscopy: patient satisfaction, safety in elderly patients, palliation, and relations with industry. Second European Symposium on Ethics in Gastroenterology and Digestive Endoscopy, Kos, Greece, July 2006. Endoscopy 2007; 39(6):556-65.

26. Chawla L. Growing up green: Becoming an agent of care for the natural world. J Dev Process 2009; 4(1):6-23

27. Strausbaugh LJ, Sukumar SR, Joseph CL. Infectious disease outbreaks in nursing homes: an unappreciated hazard for frail elderly persons. Clin Infect Dis 2003; 36(7):870-6.

28. Hughes R. Safety in nursing social research. Int J Nurs Stud 2004; 41(8):933-40.

29. Paasche-Orlow M. The ethics of cultural competence. Acad Med 2004; 79(4):347-50. 